doso en la 1

ar ejemplos a

is funcionalidac uso, dependiende encarnan los conceptos detr por e $\Lambda$ influ
$\mathrm{Pe}$ infin:

Las formas $d r$ oceso de sig ialidad .

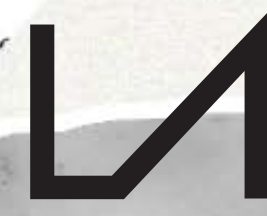

R E V I S A
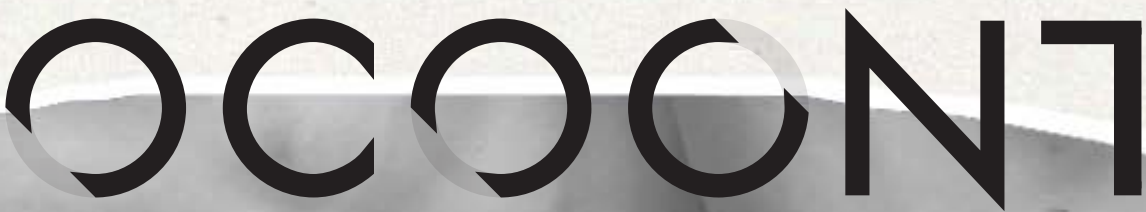

D $E$

No $6 \cdot 2019 \cdot$ ISSN 2386-8449

"El producto del diseñador es un proyecto, el estado previo de un objeto", Entrevista con Norberto Chaves, por Fernando Infante

El papel de la investigación y la teoría en diseño. Una conversación abierta, por Fernando Infante y María Jesús Godoy

UT PICTURA POESIS

Abandonar la escritura. Poesía experimental y manifiesta, Ignacio Gómez de Liaño

PANORAMA: FILOSOFÍA DEL DISEÑO Sección coordinada por Fernando Infante y María Jesús Godoy

Pensar el diseño, Fernando Infante y María Jesús Godoy (Coordinadores)

TEXTOS INVITADOS

Estatus y estado del điseño más allá del objeto, Pedro Medina Reinón

Mar de Nubes, Cuerpo de Cristal, Dionisio González

ARTÍCULOS

Understanding Design Aesthetics beyond Functional Beauty accounts, Lucía Jiménez Sánchez

Estética y diseño industrial: debates y controversias, Joan M. Marín

Del ornamento al delito. El diseño y la sociedad en Charles Baudelaire y Adolf Loos, Jorge López Lloret

When is Architecture not Design? Saul Fisher

Diseño y habitabilidad: una aproximación basada en los lenguajes de patrones, Antonio Hidalgo Pérez

Marcel Breuer: un diseñador global. Experiencias en el ámbito de la vivienda prefabricada, Salvador J. Sanchis, Ignacio Peris y Pedro Ponce Diseño y artes escénicas: el papel de Oskar Schlemmer en Das Triadische Ballett y la actualidad de la Bauhaus, Milagros García Vázquez Lo performativo en prácticas de arte y diseño actuales vinculadas a procesos de innovación social. El caso de La Venezia che non si vede y de La borda, Tània Costa Gomez

Articulaciones de la estética y el diseño. El caso de la evaluación a partir de la investigación dirigida en la carrera de diseño escénico de la Universidad de las Artes de Cuba, Mara Rodríguez Venegas y Xiomara Romero Rojas

SUPLEMENTO

El diseño, la ciudad y un lápiz de labios, Mercedes Espiau, Mar García Ranedo y Alejandro Rojas mas. 


\section{UつCつCNTE}

No $6 \cdot 2019 \cdot \operatorname{ISSN} 2386-8449 \cdot$ DOI 10.7203/LAOCOONTE.5.15381

https://ojs.uv.es/index.php/LAOCOONTE/index

COORDINACIÓN EDITORIAL

Anacleto Ferrer (Universitat de València)

Francesc Jesús Hernàndez i Dobon (Universitat de València)

Fernando Infante del Rosal (Universidad de Sevilla)

SECRETARÍA DE REDACCIÓN

Lurdes Valls Crespo (Universitat de València)

Vanessa Vidal Mayor (Universitat de València)

COMITÉ DE REDACCIÓN

Tamara Djermanović (Universitat Pompeu Fabra), Rosa Fernández Gómez (Universidad de Málaga), Anacleto Ferrer (Universitat de València), Ilia Galán (Universidad Carlos III), Ana María García Varas (Universidad de Zaragoza), María Jesús Godoy (Universidad de Sevilla), Fernando Infante del Rosal (Universidad de Sevilla), Miguel Ángel Rivero (Universidad de Sevilla), Miguel Salmerón (Universidad Autónoma de Madrid), Gerard Vilar (Universitat Autònoma de Barcelona).

COMITÉ CIENTÍFICO INTERNACIONAL

Rafael Argullol* (Universitat Pompeu Fabra), Luis Camnitzer (State University of New York), José Bragança de Miranda (Universidade Nova de Lisboa), Bruno Corà (Università di Cassino), Román de la Calle* (Universitat de València), Eberhard Geisler (Johannes Gutenberg-Universität Mainz), José Jiménez* (Universidad Autónoma de Madrid), Jacinto Lageira (Université Paris 1 Panthéon-Sorbonne), Bernard Marcadé (École Nationale Supérieure d'Arts de Paris-Cergy), Elena Oliveras (Universidad de Buenos Aires y Universidad del Salvador), Pablo Oyarzun (Universidad de Chile), Francisca Pérez Carreño* (Universidad de Murcia), Bernardo Pinto de Almeida (Faculdade de Belas Artes da Universidade do Porto), Luigi Russo (Università di Palermo), Georges Sebbag (Doctor en Filosofía e historiador del surrealismo), Zoltán Somhegyi (University of Sharjah, United Arab Emirates), Robert Wilkinson (Open University-Scotland), Martín Zubiria (Universidad Nacional de Cuyo). *Miembros de la Sociedad Española de Estética y Teoría de las Artes, SEyTA

\begin{tabular}{lll}
\hline DIRECCIÓN DE ARTE & REVISIÓN DE TEXTOS & TRANSCRIPCIÓN DE TEXTOS \\
El golpe. Cultura del entorno & Antonio Cuesta & Álvaro G. Serna
\end{tabular}

(cc) BY Excepto que se establezca de otra forma, el contenido de esta revista cuenta con una licencia Creative Commons Atribución 3.0 España, que puede consultarse en http://creativecommons.org/licenses/by/3.0/es/deed.es

EDITA

\section{SEyTA.}

CON LA COLABORACIÓN DE

\begin{tabular}{|c|c|c|c|}
\hline $\begin{array}{l}\text { VNIVERSITAT } \\
\text { ID VALENCIA } \\
\text { Institut a Creativitat } \\
\text { i|nnovacions Educatives }\end{array}$ & $\begin{array}{l}\text { VNIVERSITAT } \\
\text { IE ÖVALENCIA Departament de Filosofia }\end{array}$ & 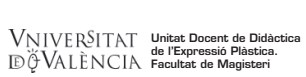 & \\
\hline $\begin{array}{l}\text { DEPARTAMENTO DE ESTÉTICA } \\
\text { E HISTORIA DE LA FILOSOFIA }\end{array}$ & $\frac{\text { UAW }}{\frac{\text { UNIVERSIDAD AUTONOMA }}{\text { DE MADRID }}}$ & $\begin{array}{l}\text { AB } \\
\text { Universitat Autònoma } \\
\text { de Barcelona }\end{array}$ & 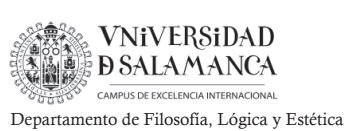 \\
\hline
\end{tabular}

LAOCOONTE aparece en los catálogos: 


\section{LつCつCN7E}

"Cuanto más penetramos en una obra de arte más pensamientos suscita ella en nosotros, y cuantos más pensamientos suscite tanto más debemos creer que estamos penetrando en ella".

G. E. Lessing, Laocoonte o los límites entre la pintura y la poesía, 1766.

Vo hay cól.

létodo, de pen.

:ión en general. Ith

zar la forma para el $\mathrm{n}$.

eptual por las orígenes

la, el objeto, la exposición

storia, porque existe en el $\mathrm{m}$

das sus raíces. Desde alli cc _. panoram

n conceptual y donde el émencia del con 'iseñado, como es el a al objeto y el di $\begin{array}{ll}\text { igen } \mathrm{de}^{\text {to }} \text { la inmer } & \text { tolvidada, o comc } \\ \text { trozo de madera ar }\end{array}$ a manera dorm comunicar ene nundo. Seguin? sngo en manos te el método $C$ les. A partir c teria prima $\mathrm{p}_{\mathbf{c}}$

'xto se puede:

¿ño, en proyea

amientos de $\mathrm{u}$

a conscie-

.)

en la publicación jue "plos de la impor te las nalidades porqu ura un ${ }^{2}$ diendo de qui zenerar $\mathrm{u}$ ción de nr? lne

in-

n-

is.

le http:,

le crear visualidades. A partir de.

ellas la propia materia prima para un en que desde un texto se puede generar $u_{11}$ i

Pensar en diseño, en proyección de nue

posibles comportamientos de una colecti

presente como una consciencia del hecho que estamos elaborando, significac

nuestro entorno (..)

Cardoso, R. C. Rafael. (2014). Design para um mundo complexo. Sãc asil: Cosac Naify. 


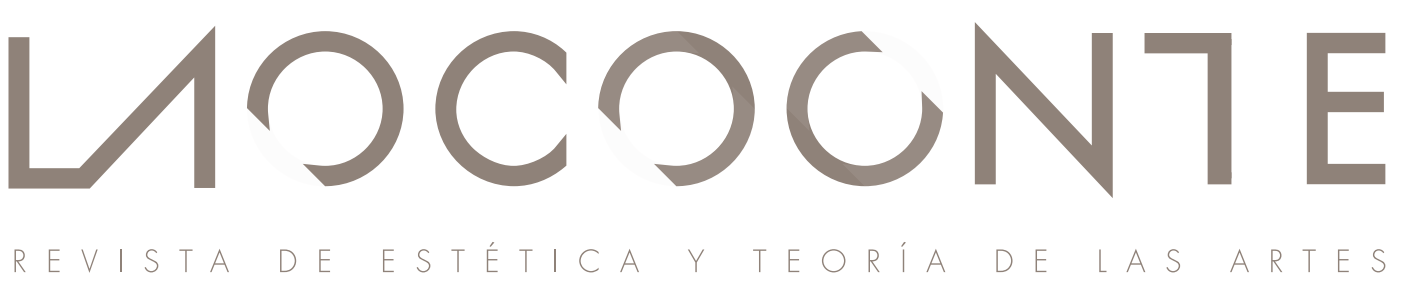

$\mathrm{N}^{\circ} 6 \cdot 2019$

PRESENTACIÓN

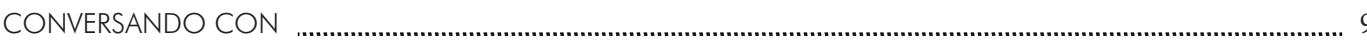

"El producto del diseñador es un proyecto, el estado previo de un objeto", Entrevista con Norberto Chaves,

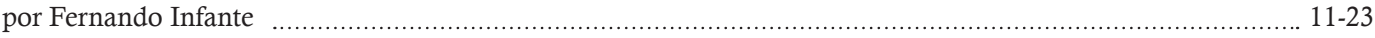

El papel de la investigación y la teoría en diseño. Una conversación abierta, por Fernando Infante

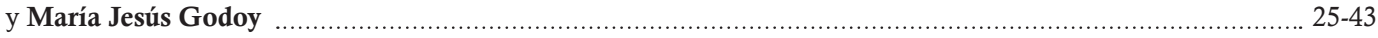

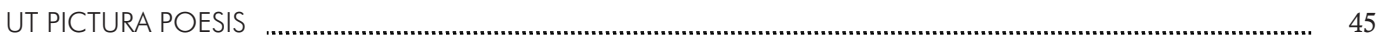

Abandonar la escritura. Poesía experimental y manifiesta, Ignacio Gómez de Liaño ................................................ 47-95

Imágenes de Laocoonte n. 6, de Isadora Gonzaga ................................................................................................... 96-97

PANORAMA

FILOSOFÍA DEL DISEÑO

Pensar el diseño, Fernando Infante y María Jesús Godoy (Coordinadores) .............................................. 101-105

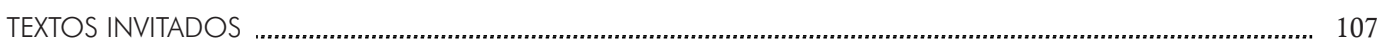

Estatus y estado del diseño más allá del objeto, Pedro Medina Reinón . ................................................... 109-125

Mar de Nubes. Cuerpo de Cristal, Dionisio González .............................................................................. 127-133

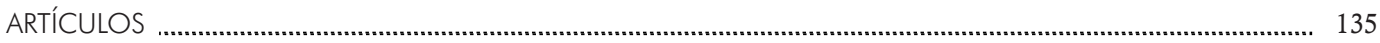

Understanding Design Aesthetics beyond Functional Beauty accounts, Lucía Jiménez Sánchez ................. 137-149

Estética y diseño industrial: debates y controversias, Joan M. Marín _...................................................... 150-164

Del ornamento al delito. El diseño y la sociedad en Charles Baudelaire y Adolf Loos, Jorge López Lloret ... $165-182$

When is Architecture not Design? Saul Fisher ……............................................................................. 183-198

Diseño y habitabilidad: una aproximación basada en los lenguajes de patrones, Antonio Hidalgo Pérez ...... 199-215

Marcel Breuer: un diseñador global. Experiencias en el ámbito de la vivienda prefabricada,

Salvador José Sanchis, Ignacio Peris y Pedro Ponce

Diseño y artes escénicas: el papel de Oskar Schlemmer en Das Triadische Ballett y la actualidad de la Bauhaus, Milagros García Vázquez

Lo performativo en prácticas de arte y diseño actuales vinculadas a procesos de innovación social.

El caso de La Venezia che non si vede y de La borda, Tània Costa Gomez

Articulaciones de la estética y el diseño. El caso de la evaluación a partir de la investigación dirigida en la carrera de diseño escénico de la Universidad de las Artes de Cuba, Mara Rodríguez Venegas

y Xiomara Romero Rojas

SUPLEMENTO 
Walter Gropius. La vida del fundador de la Bauhaus, Jorge Martínez Alcaide

¿Qué significa pensar la política desde la estética? Àger Pérez Casanovas

Ideologías estéticas en los orígenes de la pintura moderna, José Luis Plaza Chillón 300-303

Sobre a estética, Luis Carlos Pereira

Músicas populares. Sociedad y territorio: Sinergias entre investigación y docencia, Mar Aleixandre Badenes.

307-309

La necesidad de la mirada antropológica sobre la literatura, Pablo de Benito David

A propósito de Chandler, o la novela policíaca como tratado filosófico, Juan Evaristo Valls Boix

Videre aude!, Anacleto Ferrer

La inaplazable memoria del dolor y el sufrimiento, Antonio Notario Ruiz

La alargada sombra de la pintura, Raquel Baixauli

Sondear la maravilla, Juan Evaristo Valls Boix

... Y lo sabes, Marc Hernández Montoro

Arqueologías de la modernidad en las artes. Ensayo estético, Carlota Fernández-Jáuregui Rojas

Estética de la Instalación, Luis Cemillán Casis

La Herencia de otra época, María Jesús Godoy Domínguez

Del Theatrum Mundi al Gran Vidrio, Miguel Salmerón Infante

Imágenes de Isadora Gonzaga.

Fotografía de portada de Tamara Djermanovic intervenida por Isadora Gonzaga.

Los coordinadores de la sección Panorama: Filosofia del diseño agradecen

a Antonio Molina Flores su colaboración. 
ner.

llobj vidada, o de ma la publica. los de la im nalidades po ndientn $\mathrm{A}$ -
, la

que e.

usdño, si nn

ज. " da yara el mu tual y d

or enc or las orígenes un tmo, fía del diseño,

rpintero que'curra la forma de

eña Desige para un mundo complexo, de los bienes producidos por el hombre :tores subjetivos también influyen en su

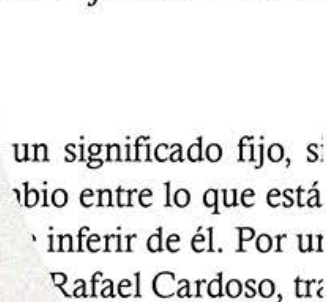

Rafael Cardoso, tri

No hay cómo no e método, de pensa 1, donde la reación en geperal. salizar la forma pa. rue amb ${ }_{\text {Snceptual por }}{ }^{1}$

$$
\text { -rola ol } n^{\prime}
$$

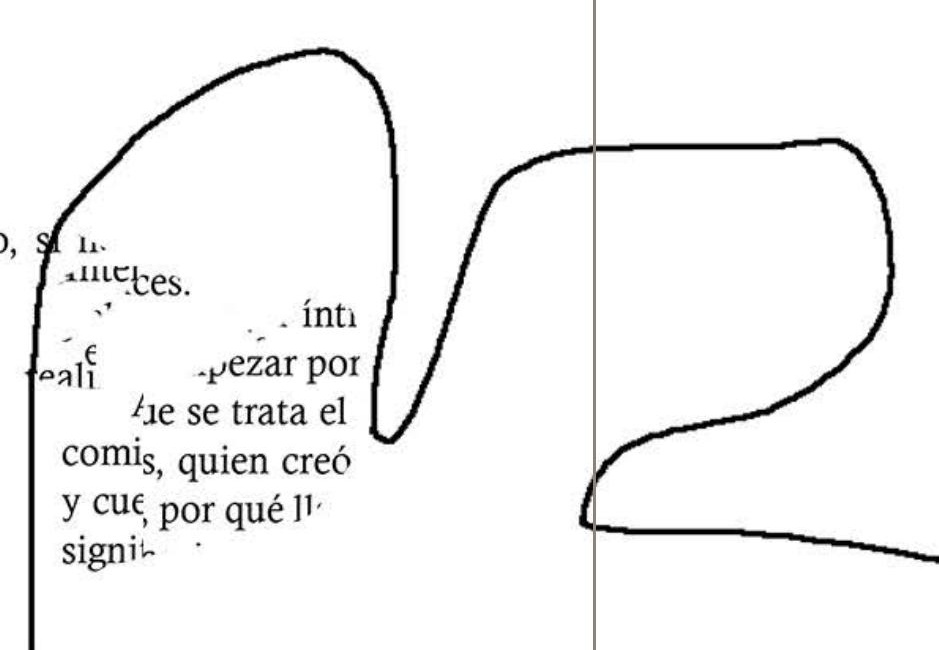

LOCOCNTE

PANORAMA: FILOSOFÍA DEL DISEÑO

Fernando Infante del Rosal y María Jesús Godoy Domínguez

(Coordinadores) 
No hay cómo no hablar de una filosofía del diseño, si no de izar la forma para el mundo sensible. Tción de formas y de la

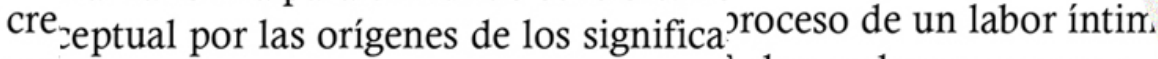

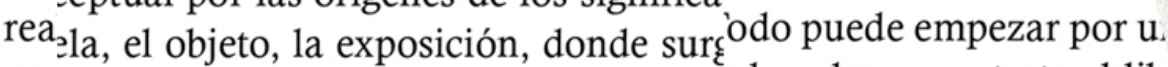

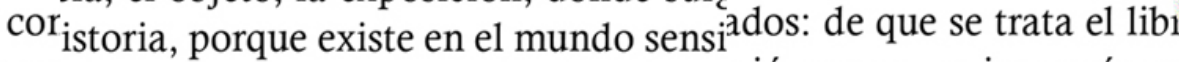
noładas sus raíces. Desde allí cojo el hilo gió, que es, quien creó y p su len conceptual y donde el está ubicado.ible o aún, por qué llama as

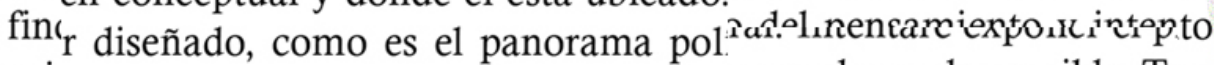
ori $_{\text {evolando la inmanencia del concepto. }}$ para el mundo sensible. Tc ce a s a forma al objeto y el diseñad ${ }^{\text {as }}$ orígenes de los significa)olo sob lengua olvidada, o como un cr la exposición, donde surg̨ido - nrocesr a un trozn de madera amnrfo le existe en el mundo sensin trai lengua olvidada,adas sus raíces. Desde allí cojo el hilona de ablo de procesc a un trozo de men conceptual y donde el está ubicado. perspectiva de lidoso en la publr diseñado, como es el panorama polndo ho, un camino diar ejemplos de levolando la inmanencia del concepto.: por una investigacióus funcionalidadı a forma al objeto y el diseñadı infl ro, el cuento, luso, dependiendı lengua olvidada, o como un $\mathrm{C} i^{\prime}$

qué, cuál e s nrecese a un trozo de madera amorfo

ata el 1

،en creó y pu.

or qué llama así, d

miento y intento a lles
- puede inferir de él. Por un in -reación ". (Rafael Cardoso, trad. 26 el ambiente que cerca el ol, especie de un danza en que ambos eleme iles son los símbolos que estso.

lmente, el contenido contextrño y hacer diseño, es antes de todo cue rna el papel de un tra o que toma la forma $\mathrm{d}^{\text {g }}$ gradual, donde la idea $\mathrm{do}_{\text {, las ideas, los relacioname }}$ danza en que ambos ropio proceso y también de r

'esign para un mundo liseñar, me planteé la cuesti' s bienes producidos por seño, es antes de tod prima eso me dá? Ejemp' es subjetivos también inf ble. Diseñar puede se ese texto, construyo el d

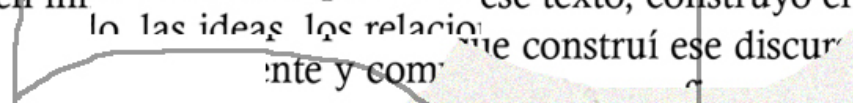

1 un significado fijo, sino que expresajue ${ }^{\dagger}$ mbio entre lo que está incrustado en Sre ¿de inferir de él. Por un lado, las form ". (Rafael Cardoso, trad. 2014)

rradual, donde la i’ 
- ormas y de rapo.

eso de un labor íntimo, un udo puede empezar por una inves 'dos: de que se trata el libro, el cu jió, que es, quien creó y por qué, ble o aún, por qué llama así, donı del pensamiento y intento a lle: Cual es el ambiente que cerca e ico. cuáles son los símholos aı

de una filosofía del diseño, si r e construcción de formas y de exponer el proceso de un labor í o sensible. Todo puede empezar los significados: de que se trata h, donde surgió, que es, quien creó y po mundo sensible o aún, por qué llama as cojo el hilo del pensamiento y intentc está ubicado. Cual es el ambiente que $\mathrm{g}$ anorama político, cuáles son los símb el concepto. Gradualmente, el conten y el diseñador encarna el papel de ur como un carpintero que toma la forr
LAU1 L11 glilla1. 111 n un sigizar la forma para e] ede inferifeptual por las orígt “. (Rafabla, el objeto, la exp istoria, porque exist y gradua adas sus raíces. De: en conceptual y do sible. $D$ : $r$ diseñado, como do, las icevolando la inman propio pri diseñar, a forma al prima e lengua olvi ese textos nrncesr a un trnzo ue construí ese discurso, he hecho de ara un reconfiguración de significado en para ilustrar... (en construccion) antiguas formas, es lanzar al mundo 1. La responsabilidad aquí se hace tamos elaborando, significados para

am mundo complexo. São Paulo,

1 agosto). Significado. Recuperado 1 br/significado/

\section{ИつCつCN7E}

PANORAMA: FILOSOFÍA DEL DISEÑO ARTÍCULOS 
- ormas y de rapon

aso de un labor íntimo, un udo puede empezar por una inves 'dos: de que se trata el libro, el cu rió, que es, quien creó y por qué, ble o aún, por qué llama así, donı del pensamiento $\mathrm{y}$ intento a lle Cual es el ambiente que cerca e ticn. cuáles son los símbolos a

de una filosofía del diseño, si r e construcción de formas y d $\epsilon$ exponer el proceso de un labor í o sensible. Todo puede empezar. los significados: de que se trata 1, donde surgió, que es, quien creó y po mundo sensible o aún, por qué llama as cojo el hilo del pensamiento y intento está ubicado. Cual es el ambiente que $q$ anorama político, cuáles son los símb lel concepto. Gradualmente, el conten y el diseñador encarna el papel de u somo un carpintero que toma la forr

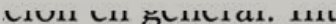
un signizar la forma para e] ambio eni ede inferieptual por las oríge n ". (Rafaəla, el objeto, la exp y gradua istoria, porque exist n danza adas sus raíces. De: en conceptual y do] sible. Dis $r$ diseñado, como do, las icevolando la inmanı ropio pri diseñar, $r$ ¥ forma al prima e lengua olvi

ese textos nrncesr a un trnzo ue construí ese discurso, he hecho de ara un reconfiguración de significado en para ilustrar... (en construccion) antiguas formas, es lanzar al mundo 1. La responsabilidad aquí se hace stamos elaborando, significados para

um mundo complexo. São Paulo,

1 agosto). Significado. Recuperado 1 $\mathrm{br} /$ significado/ 


\title{
Lo performativo en prácticas de arte y diseño actuales vinculadas a procesos de innovación social. El caso de La Venezia che non si vede y de La Borda
}

\author{
The performative in current art and design practices linked to \\ social innovation processes. The case of La Venezia che non \\ si vede and La Borda
}

Tània Costa Gomez*

\begin{abstract}
Resumen
En este artículo se propone abordar la capacidad performativa de ciertas prácticas artísticas y de diseño actuales que inciden en contextos sociales con la voluntad de afectar e influir en los estilos de vida y hábitos de lo cotidiano. En el caso del arte podría decirse que son iniciativas que cuentan con antecedentes como la tradición contemporánea de la estética relacional y el arte contextual, mientras que en diseño provienen de una visión avanzada del diseño de sistemas y servicios. En ambos casos, en esta investigación nos interesan los proyectos implicados en procesos de cambio social y que tengan como objetivo procurar vías posibles de transición hacia modos de vida sostenibles. Por lo mismo, se trata de producciones que abarcan la visión social, ética, política y estética.
\end{abstract}

Palabras clave: Arte, diseño, innovación social, performatividad, wicked problems.

\begin{abstract}
This article proposes to address the performative capacity of certain current artistic and design practices that have an impact on social contexts with the aim of affecting and influencing the lifestyles and habits of everyday life. In the case of art, it could be said that these initiatives have antecedents such as the contemporary tradition of relational aesthetics and contextual art, while in design they come from an advanced vision of the design of systems and services. In both cases, in this research we are interested in the projects involved in processes of social change that aim to provide possible ways of transition to sustainable lifestyles. For the same reason, they are productions that encompass social vision, ethics, politics and aesthetics.
\end{abstract}

Keywords: Art, design, social innovation, performativity, wicked problems.

\section{Introducción}

Observamos la dimensión performativa del arte y el diseño en aquellas prácticas que impulsan a un contexto o colectivo a la acción organizada en pos de un objetivo común, más allá de la propia dinámica artística y de diseño. Se trata, pues, de una dimensión que se realiza ya fuera de escena, por lo tanto "obscena", y que ayuda a tomar/dar forma a nuevas maneras de vivir, comportamientos alternativos y subjetividades no normativizadas.

* EINA, centro Universitario de diseño y arte adscrito a la Universidad Autónoma de Barcelona, España. 
Nuestro objeto de estudio se enfoca, pues, hacia la capacidad performativa que demuestran ciertas prácticas artísticas y de diseño actuales que no sólo pretenden desarrollarse desde la vía participativa sino que, además, se presentan como agentes de transformación en contextos de innovación social. El objetivo de tales producciones es impulsar estilos de vida y hábitos de lo cotidiano, que pudieran estar latentes o con una existencia de baja intensidad, para que activen procesos de cambio social. En este sentido, en este desarrollo entendemos la capacidad performativa del arte y el diseño como aquella que provoca modificaciones substanciales o estructurales en el contexto donde actúa, de manera que genera un movimiento que implica la creación de nuevos mundos. Por lo mismo, las prácticas aludidas proponen ir más allá de la dinámica participativa, relacional o contextual para incidir directamente en el comportamiento, formas sociales, estructuras convivenciales y consideraciones estéticas. Inevitablemente todo ello implica un posicionamiento político y ético en cuanto se sobrepasan estrategias de escenificación e, incluso, estéticas del acontecimiento (Peran 2002) con el objetivo de abordar procesos de transformación. Concretamente en esta investigación nos interesa la versión de transformación en el sentido social, o de innovación social, dejando para otros foros su interpretación relativa a transformaciones individuales, rituales o espirituales.

En el caso del arte podría decirse que son iniciativas que cuentan con antecedentes como la tradición contemporánea de la estética relacional (Bourriaud 1998) y el arte contextual (Ardenne 2002), mientras que en diseño provienen de una visión avanzada del diseño de sistemas y servicios (Polaine 2013). En ambos casos, aquí nos atañen las visiones implicadas en procesos de cambio social que tengan como objetivo procurar vías posibles de transición hacia modos de vida sostenibles. Cabe decir que en esta investigación entendemos como sostenibles tanto una concepción macro, que apunta a preocupaciones globales principalmente relacionadas con la cultura ecológica y material, como un enfoque micro, que atienda a las actividades de la vida cotidiana, las creencias y subjetividades (Rolnik y Deleuze 2006).

\section{Una perspectiva sistémica de la práctica artística y de diseño}

Las prácticas artísticas y de diseño que se enmarcan en el territorio que pretendemos trazar coinciden, también, en trabajar desde una perspectiva sistémica, incluso dentro de lo que se denominan wicked problems. Es decir, consideran el objeto de estudio o producción como una pieza más dentro de un sistema complejo, donde los componentes están interrelacionados en forma de redes distributivas y cuya resolución solo puede ser temporal y parcial ya que, tal como apunta Rittel, "el problema muta y evoluciona constantemente" (Rittel 1973). Se refiere a problemáticas globales, como la pobreza, la inmigración, la marginación, la escasez de recursos naturales, las dificultades energéticas, etc. Rittel, y más tarde Buchanan y Margolin, son los iniciadores de una perspectiva sistémica del diseño que considera cualquier asunto a trabajar dentro de una densa red de relaciones que lo condiciona y que, por lo tanto, de alguna forma ha de ser igualmente intervenida. Nos encontramos con un posicionamiento similar al elaborado a finales de los 70 por Rosalind Krauss en cuanto al campo expandido de la obra de arte, que incluye el contexto como parte significativa de la propuesta artística y que confirma su condición de obra abierta promulgada por Umberto Eco.

Esta perspectiva da pie a que ciertas prácticas artísticas y de diseño amplíen su campo de trabajo a las realidades colindantes y las influyan y modifiquen, provocando 
cambios sustanciales en su morfología, estructura y dinámica relacional. Es a partir de aquí que puede darse la posibilidad de lo performativo en el arte y el diseño, en tanto que generadores de otras narrativas de mundo o en cuanto cultivo de estilos de vida alternativos. Es en este sentido que Terry Irwin propone el diseño en transición (Transition Design) como perspectiva desde donde abordar los wicked problems y como metodología a través de la cual trabajar la transformación entendida como transición hacia un cambio de paradigma. El diseñador ha de afrontar cualquier problema de diseño desde una visión de su encaje en uno o más wicked problems y ha de iniciar el estudio del caso mapeando las relaciones a partir de la relación triádica básica entre el sujeto, los objetos hechos por el sujeto y el contexto ambiental. A partir de aquí, el desarrollo del proyecto y propuesta iterativa de diseño se dará desde la acción, en colaboración participativa, con perspectivas a largo plazo, desde la empatía y siempre como solución temporal, transicional (Irwin 2012).

Esta aportación del diseño a la comprensión de realidades complejas se apoya en la interpretación de las tesis sobre la "autopoiesis" de la organización de lo vivo de Varela, Maturana y Uribe. Concretamente en su versión de apertura a la posibilidad de aplicación a sistemas de organización social. Esto sería ya de la mano de la teoría general de los sistemas sociales desarrollada por Niklas Luhmann y por la visión sistémica de la vida de Fritjof Capra, en las que se atribuye la capacidad de autopoiesis a las estructuras sociales a partir de la premisa según la cual "The entire material world, ultimately, is a network of inseparable patterns of relationships. We have also discovered that the planet as a whole is a living, self-regulating system" (Capra 2015: 242).

III. La Venezia che non si vede, de Antoni Abad, y La Borda, cooperativa de viviendas en cesión de uso. Creación de escenarios de futuro para la transformación de estilos de vida

Para centrar esta propuesta teórica se propone un estudio de caso, a través de la comparativa entre dos proyectos de 2017: La Venezia che non si vede, del artista Antoni Abad, y La Borda, cooperativa de viviendas en cesión de uso en Barcelona. Se trata de una práctica de diseño y una artística que comparten como hilo conductor una visión ética de la problemática actual de acceso a la vivienda y gentrificación turística, en nuestro entorno urbano inmediato.

La Venezia che non si vede fue presentado en la Bienal de Venecia 2017 y, entre otras acciones, crea una aplicación de móvil (Blind.wiki) para recoger y compartir en código abierto descripciones de lugares de la ciudad de Venecia relatados por personas invidentes. Además de aportar una interpretación del lugar a través de otros sentidos, se enfatiza la importancia de la memoria colectiva y de los modos de vida de un pasado reciente en el cual la ciudad estaba habitada por los venecianos y no por los turistas.

La propuesta contaba con diversas instalaciones en el pabellón catalán de la Bienal y con otra actividad, también participativa, dirigida a la experiencia directa del espectador. El visitante tenía la oportunidad de realizar un recorrido en una embarcación tradicional veneciana, junto con una persona invidente que iba relatando su experiencia de vida como habitante de ese mismo barrio.

Por su parte, el primer edificio construido por la cooperativa de viviendas en cesión de uso La Borda ha sido diseñado por el estudio de arquitectura colaborativa La Col con la participación de las actuales usuarias. El proyecto promueve un sistema de vivienda desmarcado del mercado especulativo convencional y demuestra que es 
posible la transición hacia nuevas formas de vivir, más sostenibles social y materialmente, que comporten, finalmente, un cambio de paradigma. En efecto, el sistema de vivienda en cesión de uso comporta la no propiedad individual de la vivienda de los usuarios promotores, pero la posibilidad de continuidad del uso por sus descendientes. Cabe apuntar que la construcción abarata costes ya que el ayuntamiento cede el uso del suelo sin necesidad de compra y porque diversas fundaciones, como La Dinamo, financian estas cooperativas con recursos no públicos.

Este tipo de arquitectura colectiva se concibe en colaboración con las usuarias, se priorizan los espacios comunes que fomentan las relaciones personales, se utilizan estrategias de arquitectura ecológica para minimizar el impacto ambiental y para evitar la pobreza energética de sus habitantes.

Tanto la propuesta de Antoni Abad como la de La Borda inciden en el wicked problem que representa el acceso a la vivienda, la precarización y las desigualdades que genera la gentrificación turística. Los intentos de solución emitidos desde un paradigma convencional resultan fallidos porque no se ubican en el escenario de futuro sino en el del pasado y, por lo mismo, no tienen capacidad para atender más que aspectos parciales del conflicto. En cambio, la visión sistémica aborda la problemática en conjunto y, en lugar de plantear intervenir con/en un objeto, comunicación o espacio, piensa en diseñar un sistema que reconfigure la relación entre el usuario y la vivienda a través de la arquitectura o mediante un multiproyecto artístico. En ambos casos se pone el acento en dar paso a un nuevo paradigma, en este caso de innovación social, y en los dos proyectos se confía en la emergencia autopoiética del sistema, las relaciones que lo sustentan y sus agentes.

Para hablar/pensar en la creación/existencia de mundos futuros y llevarlos a cabo, dice Ezzio Manzini que previamente hemos de proyectar los escenarios dónde puedan realmente llevarse a cabo. El diseñador propone el SLOC scenario, es decir, un contexto pequeño, local, abierto y conectado (Small, Local, Open, Connected) como paisaje ideal para la transformación social. Y se centra en lo que llama comunidades creativas, es decir, grupos de personas que superan sus problemáticas comunes aportando soluciones creativas a través de la autogestión y que, superando el rol de usuario, se implican en la consecución de sus expectativas. El empoderamiento deviene de la combinación de los elementos adecuados al escenario requerido y de la facultad auto-otorgada de generación de conocimiento desde el mismo sistema que lo demanda, no desde una actitud de espera pasiva de recepción de gestos asistencialistas por parte del poder establecido.

También Goodman, en su teoría de la creación de mundos, plantea la premisa según la cual para crear mundos hay que partir de otros ya existentes y, para ello, expone una serie de variables posibles a través de la combinación de las cuales concebirlos. En un contexto distinto a Manzini, pero con líneas de pensamiento confluyentes, Goodman vincula la creación de mundos al conocimiento y al trabajo. Por una parte, porque si “(...) los mundos se hacen en igual medida que se encuentran, el conocimiento podrá entenderse también como un rehacer y no solo como un referir. [...] Comprensión y creación van de la mano". Y, por otra parte, porque "si es cierto que la disposición para aceptar mundos alternativos puede ser liberadora (...) también lo es que la mera aceptación complaciente de todo mundo posible no acaba por construir tampoco mundo alguno. [...] Un espíritu amplio no sustituye el trabajo" (Goodman 1990: 42, 43).

Precisamente, los proyectos de Abad y La Borda crean mundos a partir de otros 
existentes y a través de la producción creativa entendida como dispositivo de transformación de sus propios contextos. Igualmente, tales dispositivos actúan como generación de conocimiento y, por lo tanto, como investigación artística y en diseño. Dicho de otro modo, ambas propuestas desarrollan lo que Borgdorff expone como "investigación a través de la práctica del diseño y del arte" (Borgdorff 2006: 27). Es decir, un tipo de práctica artística y de diseño que es, en sí misma, investigación enfocada a la generación de conocimiento; en lugar de ser investigación que forma parte del propio proceso de producción o de utilizarse como caso de estudio para el argumentario de otras disciplinas. Asimismo, Borgdorff señala que la práctica de las artes no existe nunca aislada de su contexto y, por ello, tanto afecta como es afectada por el mismo. De esta manera, podemos añadir que los dos casos aludidos de investigación a través de la práctica de las artes y el diseño muestran su capacidad performativa en tanto crean intersticios de contenidos alternativos, en un sentido similar a los anteriormente citados Bourriaud y Hakim Bey.

\section{Lo performativo en el arte y el diseño enfocado a procesos de innovación social}

En los dos casos de estudio expuestos no se plantea una pieza de arte o un producto de diseño, sino que se genera un conjunto de acciones o actuaciones que contribuyen a convertir a los agentes implicados en agentes de cambio/para el cambio. De esta manera, nos alejamos de la idea del diseño "solo" instrumental o del arte "solo" removedor de conciencias y avanzamos hacia una concepción conjunta de incidencia sobre un estadio micro de la subjetividad y formas de vida de la cotidianidad que, a su vez, son capaces de ser replicadas y escaladas de forma que alcancen a afectar a un estadio macro para la sostenibilidad.

Es en este sentido que proponemos la consideración y, por lo tanto, denominación de este tipo de prácticas como performativas. No sólo porque se realizan desde la acción, porque ponen los cuerpos en movimiento, porque podemos tomar registro de las mismas como coreografía política. También porque tales acciones promueven cambios de vida, generan estructuras sostenibles para la comunidad y, por lo mismo, crean mundos posibles y reales. Vaya por delante que ello, además, contribuye a producir modificaciones en las subjetividades, consciencias y sistema de valores. Por esta razón el modelo es ético y político al mismo tiempo, pues afecta a esferas micro y macro en una dimensión multiescala. Y, en consecuencia, en procesos de innovación social como los estudiados, el modelo se desplaza en dirección desde lo micro a lo macro, no a la inversa. En efecto, la aspiración de La Borda es consolidar una unidad eficaz que pueda ser escalada y replicada, con las variantes necesarias para cada caso, con el objetivo de crear una red suficientemente influyente para cambiar el sistema. En el caso de la propuesta de Antoni Abad se parte de la descripción personal desde una condición particular con el objetivo de generar una red abierta de mayor alcance y, finalmente, se libera a merced de las interacciones de los participantes y se su emergencia temporal.

Inicia esta perspectiva de lo performativo el estudio comparativo entre los enunciados constatativos y los performativos desarrollado por John L. Austin en la primera conferencia de How to do Things with Words. Allí se plantea que hay enunciados que dan información (registran, describen, afirman...) y otros que, utilizando el neologismo empleado por el autor, tienen una función "realizativa". Es decir, la oración "Indica que emitir la expresión es realizar una acción y que ésta no se concibe normalmente 
como el mero decir algo", como "Cuando, con la mano sobre los Evangelios y en presencia del funcionario apropiado, digo "¡Sí, juro!”, no estoy informando acerca de un juramento; lo estoy prestando" (Austin 1955: 47).

Así pues, este uso del lenguaje no se circunscribe al objetivo de comunicar sino, también, al de actuar, hacer u operar, con lo cual se podría definir como "operativo" o "performativo". De acuerdo con el posicionamiento de Austin, en esta investigación nos hemos decantado por utilizar el término "performativo" ya que "operativo" nos remite a una interpretación demasiado connotada en cuestiones de eficiencia, viabilidad, ejecución, etc. Podríamos decir que lo performativo nos permite abrir un intersticio más allá del lenguaje con capacidad de iniciar una historia, activar un proceso, incidir en una vida. Nos vemos, pues, en condiciones de rescatar este punto in(d)icial y añadir que Austin apunta a esa zona en la que el lenguaje contiene "proyecto", de manera que representa una apertura hacia una futura acción que, en el caso del diseño y el arte, será coordinada, programada e impulsada siempre en relación con un contexto específico. En la teoría del enunciado performativo se centra esta capacidad de resorte activador en una palabra, pero, sin duda, para alcanzar un estadio performativo se necesita lo que el autor llama contexto situacional. Y éste es el que marca la diferencia de lo performativo desde una perspectiva sistémica y su oportunidad para iniciar modificaciones relacionales en un contexto.

Otra versión de lo performativo se deriva directamente de la naturaleza inestable y cambiante de la acción impulsada y así es como lo describe Allan Findeli. Según el autor, en el proceso convencional de diseño se identifica un problema A y se imagina una solución $\mathrm{B}$, resultando el proyecto de diseño como el trayecto entre A y B o el cambio de una situación a otra. En cambio, la nueva lógica de la estructura del proceso de diseño no acaba en el punto B ya que A y B no son situaciones sino partes de un sistema en el que están incluidos los usuarios y los diseñadores. Así, pues, según el autor “(...) state B is only a transitory, more or less stable, state within a dynamic process, never a solution; the production of a material object is not the only way to transform state A into state B (...)" (Findeli 2001:10).

En efecto, la transformación de un sistema no es nunca definitiva sino que se va conformando, reformando y deformando en la medida que los elementos que lo constituyen van interactuando. Es relevante el factor que señala Findeli cuando destaca que en el sistema se incluyen diseñador y usuario como agentes activos. Se observa la misma circunstancia en las prácticas artísticas como la comentada, dónde Abad emite una propuesta que se realizará de una u otra manera dependiendo de los usuarios y espectadores participantes que la construyan y del tipo de interacciones que generen con otros agentes involucrados. De hecho, la wiki.blind sigue actualmente su curso autogestionada por sus usuarios y empoderada gracias a su condición digital en código abierto alojada en una forma de red social de conocimiento. Se deduce de ello, pues, que la creación de mundos desde una perspectiva sistémica de las artes identifica esos nuevos mundos con la capacidad performativa del arte y del diseño. Apunta al respecto Findeli: "In existentialist terms, this could sound as follows: design responsibility means that designers always should be conscious of the fact that, each time they engage themselves in a design project, they somehow recreate the world" (Findeli 2001: 14). 


\section{Conclusión. Lo performativo como reencantamiento del mundo}

Cuando, por su parte, Erika Fischer-Lichte desarrolla la idea de una estética performativa pone sobre el tablero de juego una pieza principal para la presente investigación. Se trata de su vinculación a un proceso de transformación: “...los procesos de reencantamiento del mundo y la transformación de los participantes en la realización escénica" (Fischer-Lichte 2011: 361).

Cierto que otros aspectos coinciden con visiones en las que los agentes ya han modificado su identidad convencional: el artista facilitador, la autoría compartida, el espectador participante, la obra situacional. Pero el signo distintivo principal reside en su capacidad de producir transformación en el contexto en el que se desarrolle. Esta es la clave que aloja a proyectos como el de Antoni Abad o la cooperativa La Borda en un mismo territorio, que no se mide por su pertenencia a una u otra disciplina sino por su firme determinación a intervenir (ya no sólo a incidir) en entornos homogéneos para crear intersticios donde desarrollar formas de vida no normativas, alternativas.

Seguramente, esos espacios alternativos circunscritos a breves áreas delimitadas por la superficie convencional, no existirán durante mucho tiempo sin ser de nuevo engullidas por lo general. Por ello el comportamiento de las TAZ (Temporary Autonomous Zone) descritas por Hakim Bey era el de guerrilla, basado en la generación de cedulas independientes de rápida aparición y desaparición territorializando y desterritorializando el tablero de juego del poder. En cualquier caso, son situaciones emergentes que operan desde aspiraciones de invisibilidad pero con la intención de creación de autoorganizaciones sociales temporales. En el caso de la propuesta de Abad, la participación de agentes autónomos en la wiki.blind parece totalmente afín a esta premisa y, de hecho, ya había realizado anteriormente otras obras con la misma metodología participativa.

Respecto a La Borda, ciertamente no nace con vocación de provisionalidad, sino más bien de permanencia y con intención expansiva. Seguramente su naturaleza responde mejor a la perspectiva de intersticio social que Nicolas Bourriaud rescata del argumentario de Marx y que re-define de la siguiente manera: "E1 intersticio es un espacio de relaciones humanas que, insertándose más o menos armoniosa o abiertamente en el sistema global, sugiere otras posibilidades de intercambio, diferentes a las hegemónicas en dicho sistema" (Bourriaud 1997: 117).

Tanto en La Venezia che non si vede de Antoni Abad como en La Borda, lo performativo surge después de que se despliegue la acción programada, es decir, cuando empieza a emerger la fase de transformación ya emancipada. Por lo tanto, una de las conclusiones principales que se derivan de la aproximación realizada en este texto es que reconocemos el hecho performativo sólo en aquellos procesos de innovación social que se desarrollan más allá de la intervención del artista o diseñador. Desde este punto de vista, la capacidad de las propuestas artísticas y de diseño para producir una transformación social no se entendería como performativa si no ha producido una modificación estructural, que a su vez dé paso a ulteriores procesos de cambio que ya se generen y desarrollen de manera autónoma respecto a la obra o producción. Por lo mismo, una vez finalizada la fase de implementación de la obra o producción, la responsabilidad e impulso de cambio vuelve a recaer y es absorbida por los propios agentes afectados que, entonces, abandonan el rol de usuarios o espectadores para pasar a ejercer su capacidad de agencia de manera emancipada. 


\section{Bibliografía citada}

Ardenne, Paul. 2002. Un arte contextual. Creación artística en el medio urbano, en situación, de intervención, de participación Murcia: CENDEAC, 2006.

Austin, John L. 1955. How to do Things with Words. Cambridge: Harvard University Press.

Borgdorff, Henk. 2006. "El debate sobre la investigación en las artes". Cairon: revista de ciencias de la danza, ISSN 1135-9137, Nº 13, 2010.

Bourriaud, Nicolas. 1998. Esthétique relationnelle. Paris: Les presses du réel.

Capra, Fritjof. 2015. The systems view of life a unifying conception of mind, matter, and life. Cosmos and History: The Journal of Natural and Social Philosophy, vol. 11, no. $2,2015$.

Fischer-Lichte, Erika. 2011. Estética de lo performativo. Madrid: Abada. Ed. org. 2004.

Findeli, Alain. 2001. "Rethinking Design Education for the 21st Century: Theoretical, Methodological, and Ethical Discussion". Design Issues: Vol 17, N 1, pp. 10-14.

Goodman, Nelson. 1990. Maneras de hacer mundos. Madrid: Visor.

Irwin, Terry. 2012. "Wicked Problems and the Relationship Triad". Grow Small, Think Beautiful: Ideas for a Sustainable World from Schumacher College. Floris Books, 2012.

Luhmann, Niklas R. 1997. Organización y decisión, autopoiesis y entendimiento comunicativo. Barcelona: Anthropos.

Maier-Aichen, Hansjerg. 2004. "Idea Factory: un repte global en un marc de recessió mundial". Barcelona: EINA, Escola de Disseny i Art, col. PlecsEsparsos, 2004. En: Julier, Guy. La cultura del diseño. Bcn: Gustavo Gili, 2010.

Polaine, Andy y Lovlie. 2013. From Insight to Implementation Service Design. NY: Rosenfeld Media.

Rolnik, Suely y Guattari. 2006. Micropolitica. Cartografias del deseo. Madrid: Traficantes de Sueños.

Peran, Martí. 2002. Arquitecturas para el acontecimiento. Valencia: Generalitat Valenciana.

Varela, Francisco J. y Maturana. 1974. "Autopoiesis: the organization of living systems, its characterization and a model". Biosystems Volume 5, Issue 4, May 1974. 


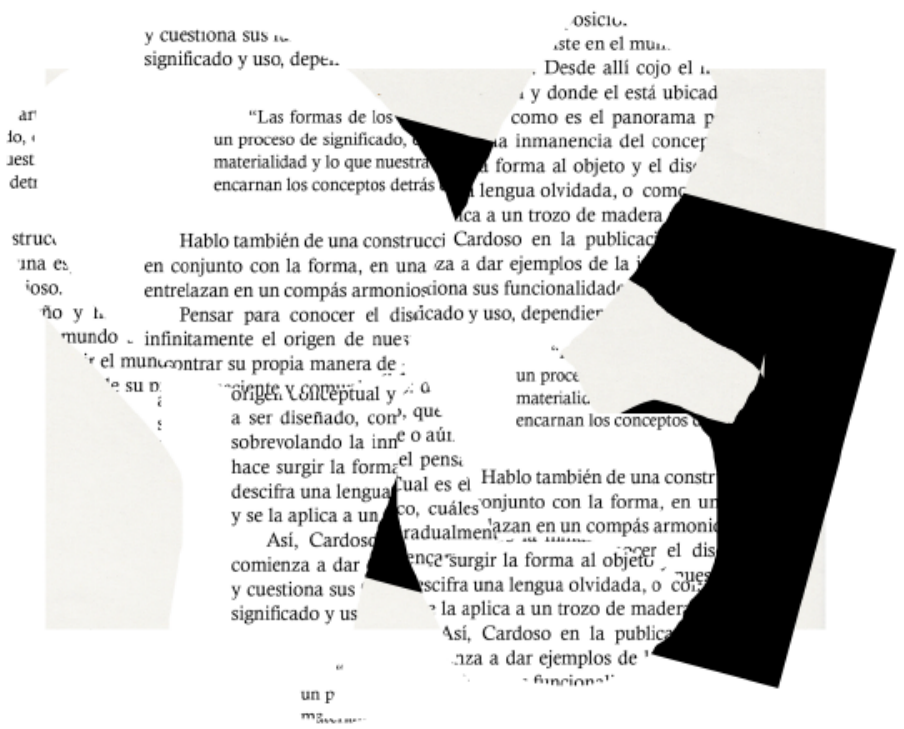

"Lo impreso exige una humildad de espíritu por cuya falta muchas de las bellas artes se tambalean ahora en experimentos de autoconciencia y sensiblería. No hay nada simple ni aburrido en lograr una página transparente. La ostentación vulgar es el doble de fácil que la disciplina".

Beatrice Warde, The Crystal Goblet, or why printings should be invisible (1930)

"El diseño que es objetivo, comprometido con el bien común, bien compuesto y delicado, constituye la base del comportamiento democrático".

Josef Müller-Brockmann, Grid and Design Philosophy (1981) 

EDITA

\section{SEyTA.}

SOCIEDAD ESPAÑLAA
DE ESTETICA Y TEORIA DE LAS ARTES

CON LA COLABORACIÓN DE

\begin{tabular}{|c|c|c|}
\hline 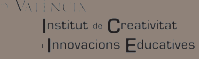 & $\begin{array}{l}\text { VNIVIRSIIN } \\
\text { II) VIIINCL Departament de Filosofia }\end{array}$ & 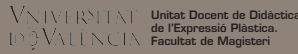 \\
\hline $\begin{array}{l}\text { ESTETICA } \\
\text { FLOSOFIA }\end{array}$ & 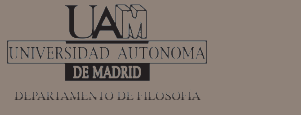 & $\begin{array}{l}\text { UAB } \\
\begin{array}{l}\text { Universitat Autònoma } \\
\text { de Barcelona }\end{array}\end{array}$ \\
\hline
\end{tabular}

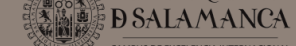

https://ojs.uv.es/index.php/LAOCOONTE/index 